\title{
Structural and Magnetic Investigations of Silica coated Cobalt- Ferrite Nanocomposites
}

\section{MEENAKSHI BANSAL, PRAVEEN AGHAMKAR and DHARAMVIR SINGH AHLAWAT*}

Department of Physics, Chaudhary Devi Lal University, Sirsa -125055 (Hry), India.

*Corresponding author E-mail: dahlawat66@gmail.com

http://dx.doi.org/10.13005/ojc/3404045

(Received: April 25, 2018; Accepted: June 07, 2018)

\begin{abstract}
Silica coated cobalt ferrite $\left(\mathrm{CoFe}_{2} \mathrm{O}_{4}: \mathrm{SiO}_{2}\right)$ nanocomposites were synthesized by co-precipitation technique using metal nitrates as precursors. The as-prepared sample has been further heat treated at $250^{\circ} \mathrm{C}, 500^{\circ} \mathrm{C}, 750^{\circ} \mathrm{C}$ and $1000^{\circ} \mathrm{C}$. Their structure and morphology related properties were desirably investigated by XRD, FTIR, TEM characterization techniques. Further, with the help of vibrating sample magnetometer (VSM) the magnetic properties have been successfully analysed. Furthermore, the structure and magnetism related properties of these nanocomposites are also understood with heating effects. With increasing calcinations temperature, crystallite size of $\mathrm{CoFe}_{2} \mathrm{O}_{4}: \mathrm{SiO}_{2}$ nanocomposites was also found to increase. The room temperature magnetic measurements have shown a strong relation of saturation magnetization, retentivity and coercivity with annealing temperature.
\end{abstract}

Keywords: $\mathrm{CoFe}_{2} \mathrm{O}_{4}: \mathrm{SiO}_{2}$ nanocomposites, co-precipitation, annealing temperature, structural, magnetic.

\section{INTRODUCTION}

Nanostructure materials because of their small size, high surface to volume ratio and quantum confinement have attracted considerable attention as compared to their bulk materials ${ }^{1,2}$. The synthesis of new nanostructure materials are of great interest to scientist and technologist. Among ferrites, the spinel ferrites are highly attractive magnetic nanoparticles because of their many uses in various fields together with permanent magnets, ferro-fluid technology, medical diagnostics, magnetic type drug delivery, microwave frequency devices, catalysis and high density information data storage ${ }^{3-9}$. In these spinel ferrites, the cobalt ferrite $\left(\mathrm{CoFe}_{2} \mathrm{O}_{4}\right)$ has been of great importance in fundamental science and technology due to their exceptional magnetic properties like large value of coercivity $(\mathrm{Hc})$, moderate type saturation magnetization (Ms), high magnitude of mechanical hardness and good chemical- stability ${ }^{10}$. As, cobalt ferrite shows inverse spinel behaviour represented by $\left(\mathrm{Co}_{1-x} \mathrm{Fe}_{x}\right) \mathrm{A}\left(\mathrm{Co}_{x} \mathrm{Fe}_{2-x}\right)$ $\mathrm{BO}_{4}$, here $\mathrm{x}$ indicates degree of inversion, while $A$ and $B$ denote tetragonal and octahedral sites respectively. However, cobalt ferrites are having very strong affinity to agglomerate, consequently it is very

This is an Open Access article licensed under a Creative Commons Attribution-Non Commercial-Share Alike 4.0 International License (https://creativecommons.org/licenses/by-nc-sa/4.0/), which permits unrestricted Non Commercial use, distribution and reproduction in any medium, provided the original work is properly cited. 
difficult to expose their distinctive physical behaviour needed for some important applications. To conquer this difficulty, nanoparticles are very well embedded in an insulating type silica matrix which allows stabilization of the nanoparticles ${ }^{11-12}$. Thus, synthesis of nanoparticles is an exciting and challenging area of research for their technological and biomedical applications. In this direction, many synthetic strategies have been developed for the preparation of nanosized spinel ferrites like ball milling, sonochemical, sol-gel, chemical co-precipitation, hydrothermal etc ${ }^{13-19}$. This paper reports about the structural and magnetic properties of nanocomposites of cobalt ferrite $\left(\mathrm{CoFe}_{2} \mathrm{O}_{4}\right)$ dispersed in silica matrix fabricated by co-precipitation technique. Moreover, temperature dependent investigations of their properties have also been carried out.

\section{MATERIALS AND METHODS}

\section{Sample Preparation}

Various nanocomposites samples of cobalt ferrites in silica $\left(\mathrm{CoFe}_{2} \mathrm{O}_{4}: \mathrm{SiO}_{2}\right)$ were prepared and synthesized with the help of co-precipitation technique as described below:

Preparation of $\mathrm{CoFe}_{2} \mathrm{O}_{4}$ was carried out by using high purity precursors of nitrates: cobalt nitrate hexahydrate $\left(\mathrm{Co}\left(\mathrm{NO}_{3}\right)_{2} \cdot 6 \mathrm{H}_{2} \mathrm{O}\right)$, ferric nitrate nonahydrate $\left(\mathrm{Fe}\left(\mathrm{NO}_{3}\right)_{3} \cdot 9 \mathrm{H}_{2} \mathrm{O}\right)$, ammonia hydroxide $\left(\mathrm{NH}_{4} \mathrm{OH}\right)$. In this method $\mathrm{Co}\left(\mathrm{NO}_{3}\right)_{2} \cdot 6 \mathrm{H}_{2} \mathrm{O}$ and $\mathrm{Fe}\left(\mathrm{NO}_{3}\right)_{3} \cdot 9 \mathrm{H}_{2} \mathrm{O}$ were taken in the form of molar ratio $1: 2$ of $\left[\mathrm{Co}^{2+}\right] /\left[\mathrm{Fe}^{3+}\right]$ and then were dissolved in double distilled water with stirred briskly at $70^{\circ} \mathrm{C}$. In this work, double distilled water was used as a solvent in order to avoid impurities. A brown coloured clear solution was obtained. Ammonia hydroxide was used as a base to get the precipitates of $\mathrm{CoFe}_{2} \mathrm{O}_{4}$ solution. Afterwards resultant solution was filtered with double distilled water by many times to remove impurities. Dark brown precipitates of $\mathrm{CoFe}_{2} \mathrm{O}_{4}$ in the form of suspension solution were obtained.

Next step was synthesis of $\mathrm{SiO}_{2}$ solution. For that a typical molar ratio of TEOS: $\mathrm{C}_{2} \mathrm{H}_{5} \mathrm{OH}$ : $\mathrm{HNO}_{3}$ : $\mathrm{H}_{2} \mathrm{O}$ : $\mathrm{NH}_{4} \mathrm{OH}$ precursors was taken as 1: 3: 0.01:1: 0.016 respectively. After that $\mathrm{NH}_{4} \mathrm{OH}$ has been added drop wise in the solution mixture of TEOS, $\mathrm{C}_{2} \mathrm{H}_{5} \mathrm{OH}$ and $\mathrm{HNO}_{3} . \mathrm{NH}_{4} \mathrm{OH}$ turned the solution mixture of TEOS, $\mathrm{C}_{2} \mathrm{H}_{5} \mathrm{OH}$ and $\mathrm{HNO}_{3}$ from transparent to milky.
Further, this suspension- solution was very well stirred continuously for $2 \mathrm{~h}$ at $60^{\circ} \mathrm{C}$.

In the third and final step, synthesis of $\mathrm{CoFe}_{2} \mathrm{O}_{4}: \mathrm{SiO}_{2}$ nanocomposites was carried out by mixing suspension solution obtained in the first and second steps. The mixed suspension solution was stirred for 6 hours. This resulted in the formation of precipitates of $\mathrm{CoFe}_{2} \mathrm{O}_{4}: \mathrm{SiO}_{2}$. Precipitates so obtained were filtered, washed and dried carefully at $80^{\circ} \mathrm{C}$ in a vacuum-oven overnight. These dried precipitates were grinded into a very fine-powder. Finally, this fine-powder was further heat treated at $250^{\circ} \mathrm{C}, 500^{\circ} \mathrm{C}, 750^{\circ} \mathrm{C}$ and $1000^{\circ} \mathrm{C}$ in vacuum using a programmable vacuum muffle furnace.

\section{Instrumentation}

XRD: Measurements of XRD data was carried out by an X-ray diffractometer (Philips $\mathrm{PW} / 1710$ ) using mono-chromatic CuK $\alpha$ type radiation of wavelength $1.548 \AA$ ( $50 \mathrm{KV}, 40 \mathrm{~mA})$. XRD pattern provides information regarding crystallite size, strain and lattice parameter.

FTIR: The FTIR spectra were recorded by using FTIR spectrometer (Perkin-Elmer 1600) to study information like phase transformation and bonding of constituents in the frequency range $7800-350 \mathrm{~cm}^{-1}$.

TEM: Surface morphology and microstructure of nanocrystallites was analysed by transmission electron microscopy (TEM-TECNAI 200kV) in vacuum with a maximum applied voltage $200 \mathrm{kv}$.

VSM: Measurements of magnetic properties of our prepared ferrites samples were performed at room temperature with the help of a vibrating sample magnetometer (VSM) Model ADE-EV9 under highest magnetic field of 2.2 Tesla.

\section{RESULTS AND DISCUSSION}

\section{XRD Analysis}

Recorded XRD pattern for $\mathrm{CoFe}_{2} \mathrm{O}_{4}: \mathrm{SiO}_{2}$ of various samples, as-prepared along with heat treated type at temperatures $250^{\circ} \mathrm{C}, 500^{\circ} \mathrm{C}$ and $750^{\circ} \mathrm{C}$ are shown in Fig.1. A broad hump at $2 \theta$ around $\sim 18-23^{\circ}$ in all these XRD traces attribute to amorphous like nature of $\mathrm{SiO}_{2}$ material. The XRD results of as-prepared sample shows weak nature of peaks indicating poor crystallinity. For the purpose 
of investigation about the effect of heat treatment on precursors, the as-prepared sample was calcined at low temperature around at $250^{\circ} \mathrm{C}$ for 2 hour. Results of XRD for the sample calcined at $250^{\circ} \mathrm{C}$ also showing weak type peaks pointing for poor crystallinity. Further, the as-prepared sample was heat treated at higher temperatures $500^{\circ} \mathrm{C}(2 \mathrm{~h})$ and $750^{\circ} \mathrm{C}$ ( 2 hour). Analysis of the Fig. 1 indicates that the rise in temperature leads to better crystallinity of the sample calcined at $500^{\circ} \mathrm{C}$. In the diffraction patterns of sample, heat treated from $250^{\circ} \mathrm{C}-500^{\circ} \mathrm{C}$ the peak at $2 \theta \sim 33^{\circ}$ could be assigned as characteristic peak of $\alpha-\mathrm{Fe}_{2} \mathrm{O}_{3}{ }^{20}$ while peak centred at $2 \theta \sim 35^{\circ}$ could be assigned as characteristic peak for synthesized material $\mathrm{CoFe}_{2} \mathrm{O}_{4}: \mathrm{SiO}_{2}$ (JCPDS PDF card no. 221086). From the Fig. 1 , the intensity of $\alpha-\mathrm{Fe}_{2} \mathrm{O}_{3}$ peak is found higher than that at $2 \theta \sim 35^{\circ}$. It indicates that ferrite phase is leading the $\mathrm{CoFe}_{2} \mathrm{O}_{4}$ phase in this temperature range. Related literature reveals that ferrite silica composite has mostly been calcined in the temperature range $300-700^{\circ} \mathrm{C}^{21}$. For our interest to study the effect of recrystallization temperature on ferrite: silica composite, we calcined the as prepared sample at $750^{\circ} \mathrm{C}$ for 2 hour. The XRD pattern of this sample is showing sharp and intense peaks at $20 \sim 30.10,33.20\left(^{*}\right), 35.57,43.16,54.10,57.08$, 62.65 which have also been indexed by comparing with (JCPDS PDF card no. 22-1086) to the cubic-spinel structure (Fd3M) of $\mathrm{CoFe}_{2} \mathrm{O}_{4}$. However, it is highly interesting to note that intensity of peak centred at $2 \theta \sim 35.57^{\circ}$ has increased while that of centred at $2 \theta \sim 33.20^{\circ}$ is reduced for the sample at $750^{\circ} \mathrm{C}$. This increase of sharp intensity peak centred at $2 \theta$ value near about $35.57^{\circ}$ reveals that $\mathrm{CoFe}_{2} \mathrm{O}_{4}$ particles have nucleated in the silica matrix.

The change in lattice parameters at

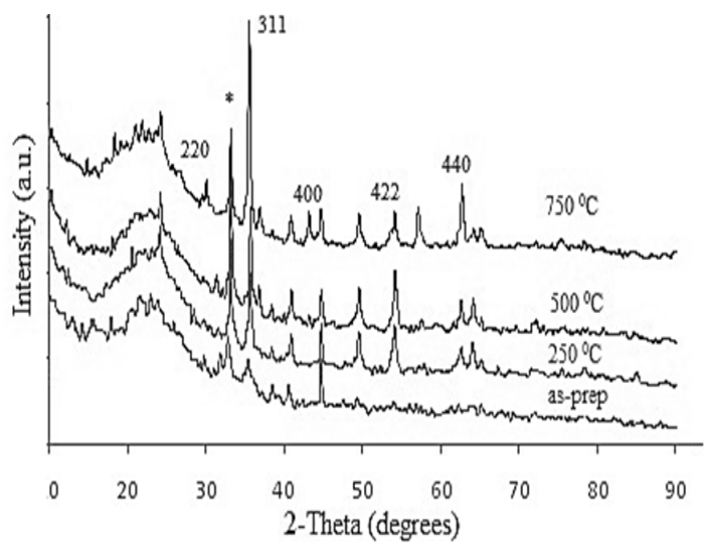

Fig.1. Recorded XRD patterns of as-prepared and thermally treated samples of $\mathrm{CoFe}_{2} \mathrm{O}_{4}: \mathrm{SiO}_{2}$ at different temperatures

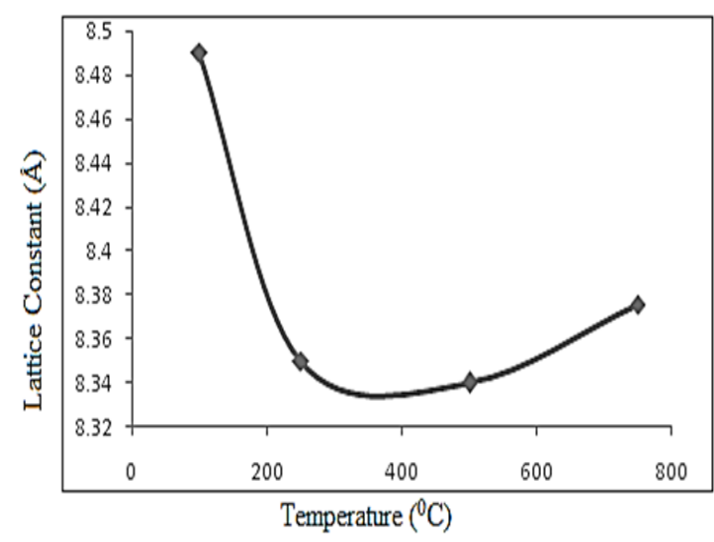

Fig.2. Lattice constant versus calcinations temperature

different temperatures is also reported in the Fig. 2. The lattice parameter of the sample shows a polynomial dependence on calcinations temperature. This variation in lattice parameters are mainly due to: (i) simple thermal changes, and (ii) the changes in cation distribution. The results of present investigation concludes that lattice constant decreases with increasing temperature up to $250^{\circ} \mathrm{C}$ and however, a sudden change in lattice constant with temperature is also observed which may be due to orderingdisordering transformation in the spinel. The grain size $\left(D_{D-S}\right)$ of nanocomposites was also estimated by Debye-Scherrer equation ( 1$)^{22}$ and the size-strain plot have been shown in the Figure 3.3.

$\beta=k \lambda / D_{D-S} \cos \theta$

The mean crystallite size of $\mathrm{CoFe}_{2} \mathrm{O}_{4}$ : $\mathrm{SiO}_{2}$ was estimated corresponding to the strongest reflection near about $35.57^{\circ}$.It is a well known fact that the grain size and micro-strain produces peak broadening. This could be due to the stresses and faults inside the prepared spinel nanoparticles. The effects of grain size and strain have to be distinguished. Although, these both type effects are independent and may be understood with the help of size-strain plot. This plot for size-strain may also be known as Williamson-Hall plot. On the other hand, the particle size $\left(D_{\mathrm{W}-\mathrm{H}}\right)$ was also calculated by considering the stress broadening with the use of Williamson- Hall method.

$\beta=k \lambda / D_{W-H} \cos \theta+4 \varepsilon \sin \theta$

Where $\varepsilon$ is stress coefficient Micro-strain values have been obtained from slope of these fitted lines. The value of standard deviation estimated 
to be is 0.00121 . The increase in particle size has been noticed from the $\mathrm{W}-\mathrm{H}$ plot as compared to Debye-Scherrer equation. This increase in size by $\mathrm{W}-\mathrm{H}$ plot method is due to the consideration of stress effects. By fitting the data, the average grain size $\left(D_{\text {W-H }}\right)$ and micro-strain $(\varepsilon)$ are estimated and given in the Table 1.The interplaner spacing(d) and lattice parameter (a) are determined to be $2.52536 \AA$ and $8.376 \mathrm{~nm}$ respectively corresponding to the most prominent- peak (311) by using Bragg's equation.

$$
\mathrm{d}=\frac{\mathrm{a}}{\sqrt{\mathrm{h}^{2}+\mathrm{k}^{2}+\mathrm{l}^{2}}}
$$

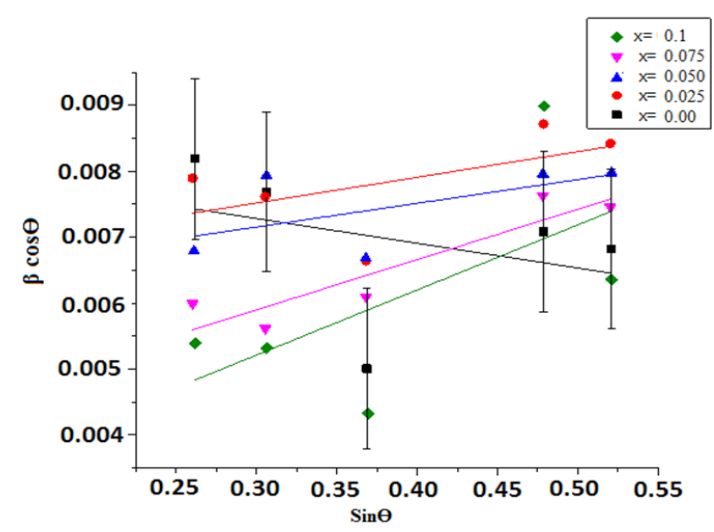

Fig. 3. Williamson-Hall plot of as-prepared and calcined $\mathrm{CoFe}_{2} \mathrm{O}_{4}: \mathrm{SiO}_{2}$ nanocomposites at different temperatures

These values have been found in good agreement with the already reported results by other researchers ${ }^{20}$. Activation energy of nanoparticles is calculated from the Scott's equation.

$\mathrm{D}=\mathrm{C} \exp (-\mathrm{E} / \mathrm{RT})$

(4)
From the Fig. 4, an almost linear relationship between crystallite sizes and calcinedtemperature indicates that crystallite grows primarily by means of an interfacial reaction in $\mathrm{CoFe}_{2} \mathrm{O}_{4}$ : $\mathrm{SiO}_{2}$ and was easily affected by the calcinations conditions. The obtained value of activation energy is $\mathrm{E}=0.22 \mathrm{eV}$.

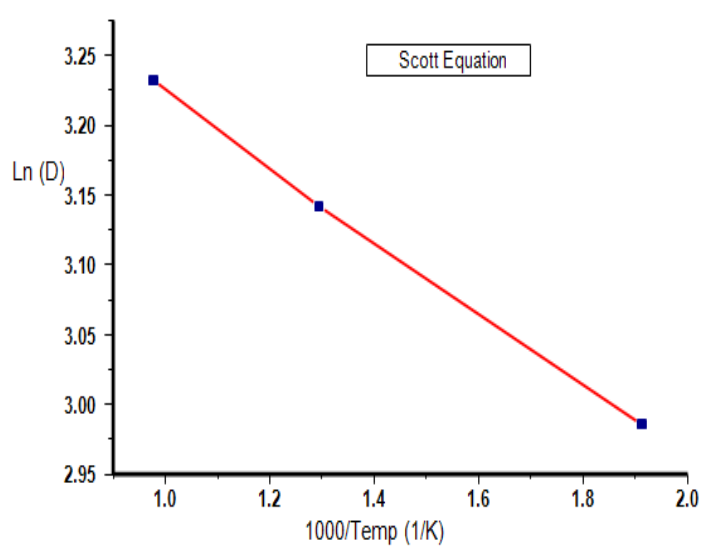

Fig.4: Crystallite size versus calcinations temperatures formula

The X-ray density is estimated by using the

$\rho X=8 M N a^{3}$

Where as a, $\mathrm{N}$ and $\mathrm{M}$ are lattice constant, Avogadro's number and molecular weight respectively. From the Table 1, it could be seen that around the re-crystallization temperature, dislocations (micro grains) creates strain and thus main lattice defect occurs, which decreases with further increase in temperature as written in the Table 1.

Table 1 : Structural-parameters of $\mathrm{CoFe}_{2} \mathrm{O}_{4}: \mathrm{SiO}_{2}$ nanocomposites at different temperatures.

\begin{tabular}{lccccc}
\hline $\begin{array}{l}\text { Calcinations } \\
\text { Temp.\& Time }\end{array}$ & $\begin{array}{c}\text { Crystallitesize } \\
\mathrm{D}_{\mathrm{D}-\mathrm{s}}(\mathrm{nm})\end{array}$ & $\begin{array}{c}\text { Average Crystallitesize } \\
\mathrm{D}_{\text {W-H }}(\mathrm{nm})\end{array}$ & Strain $(\varepsilon)$ & $\begin{array}{c}\text { Lattice constant } \\
(\AA)\end{array}$ & $\begin{array}{c}\text { X-ray } \\
\text { density }\left(\mathrm{g} / \mathrm{cm}^{3}\right)\end{array}$ \\
\hline $250^{\circ} \mathrm{C}(2 \mathrm{~h})$ & 19.80 & 20.26 & $1.01 \times 10^{-2}$ & 8.032 & 6.72 \\
$500^{\circ} \mathrm{C}(2 \mathrm{~h})$ & 27.15 & 28.95 & $2.72 \times 10^{-3}$ & 8.062 & 6.75 \\
$750^{\circ} \mathrm{C}(2 \mathrm{~h})$ & 35.34 & 38.76 & $3.75 \times 10^{-3}$ & 8.069 & 6.66 \\
\hline
\end{tabular}

\section{FTIR Study}

The FTIR spectra of different samples like (a) as-prepared and those calcined at (b) $250^{\circ} \mathrm{C}$ (c) $500^{\circ} \mathrm{C}$ and (d) $750^{\circ} \mathrm{C}$ for $2 \mathrm{~h}$ in wave number 4000-400 cm-1 range is shown in the Fig. 5 . Spectra related to as-prepared sample of $\mathrm{CoFe}_{2} \mathrm{O}_{4}$ :
$\mathrm{SiO}_{2}$ shows bands at $3398.5 \mathrm{~cm}^{-1}$ and $3404 \mathrm{~cm}^{-1}$ which have been assigned to the stretchingvibration $(\mathrm{H}-\mathrm{O}-\mathrm{H})$ and surface silanol-group $(\mathrm{Si}-\mathrm{OH})$ respectively. From this spectrum, broadening of the band has been confirmed as a result of the water band overlaps with surface hydroxyl group vibrations. 
Further, the presence of strong absorptions at 1095.57, 798.53 and $464.84 \mathrm{~cm}^{-1}$ indicate about the formation of silica network ${ }^{23}$. In our samples, the appearance of Si-O-Fe band at $956.69 \mathrm{~cm}^{-125}$ along with $\mathrm{Si}-\mathrm{O}-\mathrm{H}$ and $\mathrm{Co}-\mathrm{O}$ bonds indicates about the chemical nature of transition metals. According to this, the transition metal ions do not involve directly in the sol-gel chemical process even though they were added into our starting solutions ${ }^{24}$. In the sample's spectra calcined at $250^{\circ} \mathrm{C}$, band at $1650 \mathrm{~cm}^{-1}$ could be understood due to the deformation process of water molecules. For the samples thermally treated at $500^{\circ} \mathrm{C}$, absorption band of $\mathrm{SiO}_{4}$ tetrahedron at $1095.57 \mathrm{~cm}^{-1}$ for Si-O-S vibration has further broadened more. However, $\mathrm{O}-\mathrm{Si}-\mathrm{O}$ symmetric bond stretching vibrations at $464.84 \mathrm{~cm}^{-1}$ and vibrational mode of Si-O-Si bond present at $800 \mathrm{~cm}^{-1}$ have become more weaker. This may be understood as rearrangement process in silica network ${ }^{25}$. However, band centred around $956 \mathrm{~cm}^{-1}$ show an increase in the intensity that may be believed due to the absorption by $\mathrm{Fe}-\mathrm{O}$ stretching in $\mathrm{Fe}-\mathrm{O}-\mathrm{Si}$ bonds. All these facts lead to the formation of $\mathrm{CoFe}_{2} \mathrm{O}_{4}$ clusters accompanied with the rearrangement of silica network. These nanocrystallies formation is believed to be possible with the enhancement of

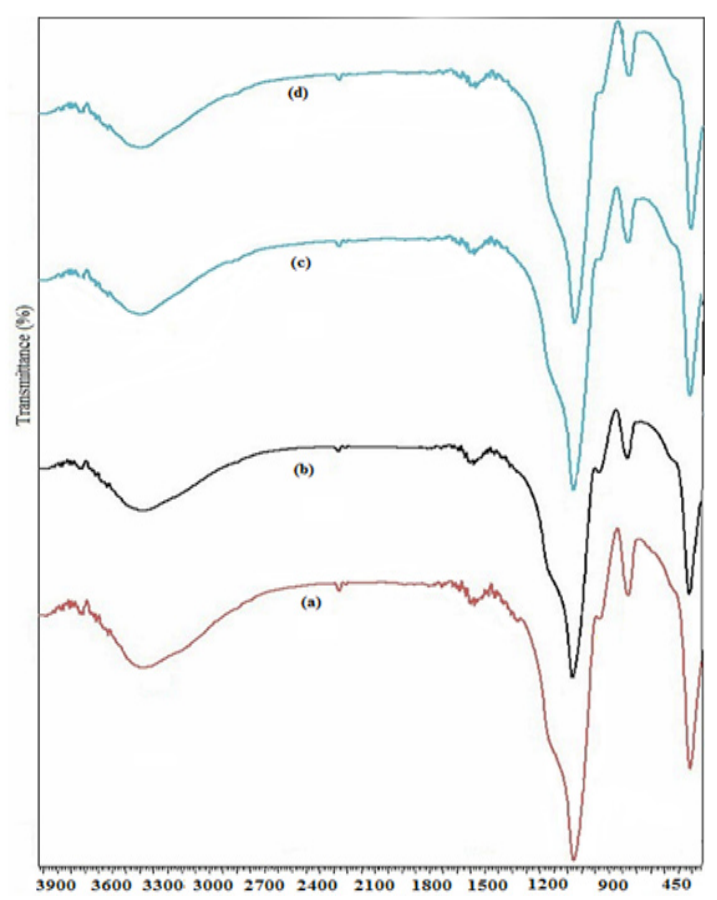

Fig. 5. FTIR spectra of $\mathrm{CoFe}_{2} \mathrm{O}_{4}: \mathrm{SiO}_{2}$ nanocomposites calcined at different temperatures: (a) as-prepared (b) $250^{\circ} \mathrm{C}$ (c) $500^{\circ} \mathrm{C}$ and (d) $750^{\circ} \mathrm{C}$ the $\mathrm{Si}-\mathrm{O}-\mathrm{Fe}$ bond between the $\mathrm{CoFe}_{2} \mathrm{O}_{4}$ clusters and surrounding silica network. Furthermore, for the samples heat treated at $750^{\circ} \mathrm{C}$, the absorption at $1095 \mathrm{~cm}^{-1}$ for $\mathrm{Si}-\mathrm{O}-\mathrm{Si}$ of the $\mathrm{SiO}_{4}$ tetrahedron grows narrower and stronger, while the band at 956 $\mathrm{cm}^{-1}$ was disappeared ${ }^{23}$. Poor quality development of ferrite-structure in our as-prepared sample is supported by the weakening of characteristicband of ferrite $\left(590 \mathrm{~cm}^{-1}\right)$. In fact, this is in good agreement with our XRD results that have shown poor crystallinity in our as-prepared samples. Moreover, at high temperature absence of water molecules and $\mathrm{Si}-\mathrm{OH}$ volatiles from our sample leads to densification of $\mathrm{CoFe}_{2} \mathrm{O}_{4}: \mathrm{SiO}_{2}$ justifying for the formation of nanocomposites which is confirmed by XRD results.

\section{TEM Analysis}

The morphology of the samples of $\mathrm{CoFe}_{2} \mathrm{O}_{4}: \mathrm{SiO}_{2}$ nanocomposites annealed at (a) $750^{\circ} \mathrm{C}$ and (b) $1000^{\circ} \mathrm{C}$ for $2 \mathrm{~h}$ has been analysed by TEM measurements as exhibited in the Fig. 6 . Average particle-size of nanocomposites annealed at (a) $750^{\circ} \mathrm{C}$ and (b) $1000^{\circ} \mathrm{C}$ is found approximately $35 \mathrm{~nm}$ and $38 \mathrm{~nm}$ respectively which are in good agreement with the value obtained by XRD data, $38.76 \mathrm{~nm}$ at $750^{\circ} \mathrm{C}$. It may be mentioned from resemblance of TEM results with XRD for particle size and then sharpness of XRD peaks that recorded micrographs indicate good quality samples and appearing approximate spherical shape $\mathrm{CoFe}_{2} \mathrm{O}_{4}$ nanoparticles with silica ${ }^{26}$. As the existence of nanocomposites of $\mathrm{CoFe}_{2} \mathrm{O}_{4}$ embedded in silica network is supported by FTIR analysis. Histograms of $\mathrm{CoFe}_{2} \mathrm{O}_{4}: \mathrm{SiO}_{2}$ nanocomposites shown in the Fig. 7 annealed at (a) $750^{\circ} \mathrm{C}$ and (b) $1000^{\circ} \mathrm{C}$ reveal an important information that nearly $75 \%$ of crystallites are having their size range of $30-42 \mathrm{~nm}$ representing a wide grain size distribution of crystallites.

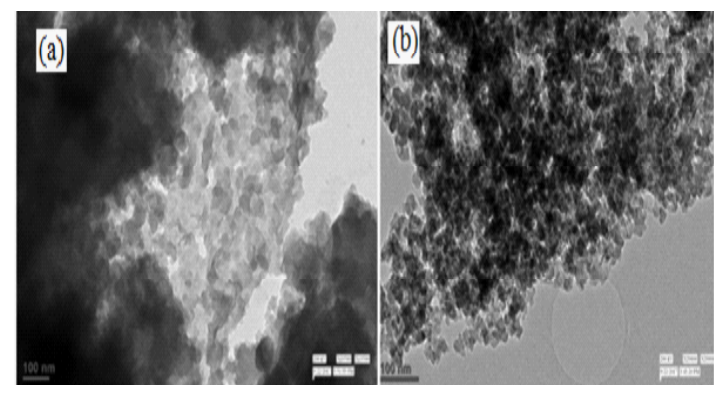

Fig. 6. TEM micrograph of $\mathrm{CoFe}_{2} \mathrm{O}_{4}: \mathrm{SiO}_{2}$ nanocomposites annealed at (a) $750^{\circ} \mathrm{C}$ and (b) $1000^{\circ} \mathrm{C}$ 

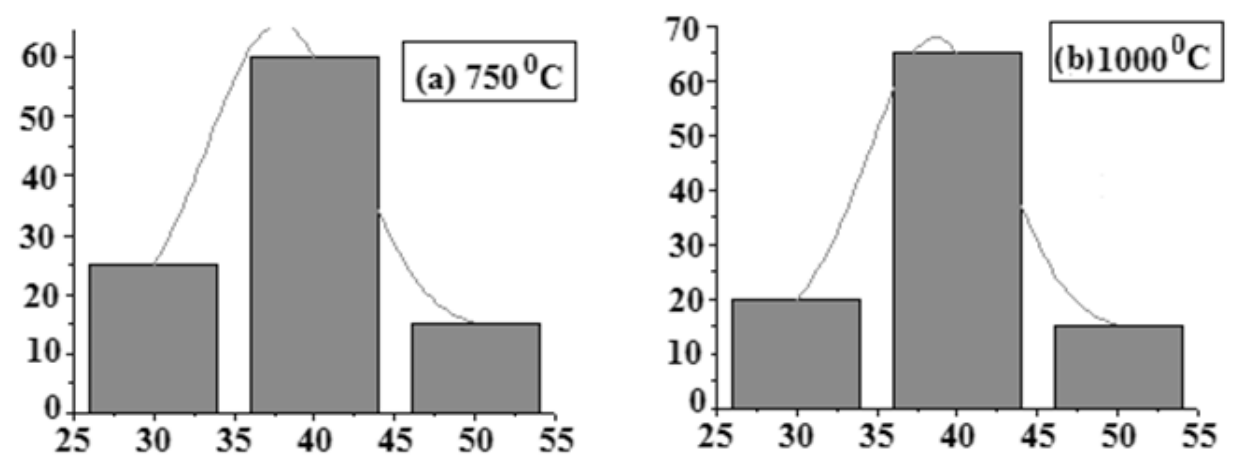

Fig. 7. Histograms $\mathrm{CoFe}_{2} \mathrm{O}_{4}: \mathrm{SiO}_{2}$ nanocomposites annealed at (a) $750^{\circ} \mathrm{C}$ and (b) $1000^{\circ} \mathrm{C}$

\section{VSM Study}

The $\mathrm{M}-\mathrm{H}$ curves of samples observed at three different values of temperatures are shown in the fig8. Important magnetic parameters like saturation magnetisation (Ms), residual magnetization $(\mathrm{Mr})$ and coercivity $(\mathrm{Hc})$ have been listed in the Table 2. These results indicate that above mentioned all these magnetic properties of $\mathrm{CoFe}_{2} \mathrm{O}_{4}: \mathrm{SiO}_{2}$ nanocomposites show highly dependence behaviour upon the calcinations temperature. The value of Ms enhances from $53.6 \pm 0.1 \mathrm{emu} / \mathrm{g}$ to $55.3 \pm 0.1 \mathrm{emu} / \mathrm{g}$ and from $55.3 \pm 0.1 \mathrm{emu} / \mathrm{g}$ to $63.7 \pm 0.1 \mathrm{emu} / \mathrm{g}$ with the increase of temperature from $250^{\circ} \mathrm{C}$ and $500^{\circ} \mathrm{C}$ and from $500^{\circ} \mathrm{C}$ to $1000^{\circ} \mathrm{C}$ respectively. However, these values of saturation magnetization of silica coated cobalt-ferrite nanocrystallites were found smaller as compared to their bulk size value of $80.8 \mathrm{emu} / \mathrm{g}^{27}$. This could be explained with the help of core- shell model, it states about the finite size effects of nanoparticles that lead to spin non-colinearity at surface, and consequently magnetization reduces ${ }^{20}$. A similar kind evolution process may also be found for $\mathrm{Mr}$, from $15.48 \mathrm{emu} \mathrm{g}^{-1}$ at $250^{\circ} \mathrm{C}$ to $21.48 \mathrm{emu} \mathrm{g}^{-1}$ at $500^{\circ} \mathrm{C}$. But when samples are heat treated at $1000^{\circ} \mathrm{C}$ a decrease in $\mathrm{Mr}$ is observed leading to surface canting effects as seen from the Table 2. It can be deduced from the evolution behaviours of Ms and $\mathrm{Mr}$ that are highly dependent upon the growth of $\mathrm{CoFe}_{2} \mathrm{O}_{4}: \mathrm{SiO}_{2}$ nanosize crystallites. As the calcinations temperature is raised from $250^{\circ} \mathrm{C}$ to $500^{\circ} \mathrm{C}$ an increase in the values of $\mathrm{Mr}$, Ms and average crystallite-size has been observed, given in the Table1. Thus, modification in magnetic properties of cobalt-ferrite has been attributed to variation of particle size as a function of temperature. From the data of Table 2, it may be noticed from variation of $\mathrm{Hc}$ value that its behaviour is different as compared to Ms and Mr values which indicates that size of nanocrystallites is not the only factor in deciding $\mathrm{Hc}$ values. It has been concluded by many other researchers that value of $\mathrm{Hc}$ is highly related with many factors like microstructure, particle/grain size and residual strain ${ }^{28-29}$. The coercivity $(\mathrm{Hc})$ varied from 23630 e to 21810 e with temperature from $250^{\circ} \mathrm{C}$ to $1000^{\circ} \mathrm{C}$. The coercivity for pure $\mathrm{CoFe}_{2} \mathrm{O}_{4}$ nanoparticles is reported to be lower (980 Oe) as compared to $\mathrm{CoFe}_{2} \mathrm{O}_{4} / \mathrm{SiO}_{2}$ nanoparticles ${ }^{30}$. This large difference may be understood by the coating of $\mathrm{SiO}_{2}$ on $\mathrm{CoFe}_{2} \mathrm{O}_{4}$, that causes from surface effects.

Table 2: Magnetic parameters of $\mathrm{CoFe}_{2} \mathrm{O}_{4}: \mathrm{SiO}_{2}$ nanocomposites

\begin{tabular}{ccccc}
\hline Calcinations Temperature $\left({ }^{\circ} \mathrm{C}\right)$ & $\mathrm{M}_{\mathrm{s}}(\mathrm{emu} / \mathrm{g})$ & $\mathrm{M}_{\mathrm{r}}(\mathrm{emu} / \mathrm{g})$ & $\mathrm{H}_{\mathrm{c}}(\mathrm{Oe})$ & $\mathrm{R}=\mathrm{M}_{\mathrm{r}} / \mathrm{M}_{\mathrm{s}}$ \\
\hline 250 & $53.6 \pm 0.1$ & 15.48 & 2363 & 0.29 \\
500 & $55.3 \pm 0.1$ & 21.48 & 2363 & 0.39 \\
1000 & $63.7 \pm 0.1$ & 19.79 & 2181 & 0.31 \\
\hline
\end{tabular}

From the Table 2, values of remnant ratio $\mathrm{R}=\mathrm{Mr} / \mathrm{Ms}$ indicate that direction of magnetization easily reorients to its nearest axis direction after removal of magnetic field. 


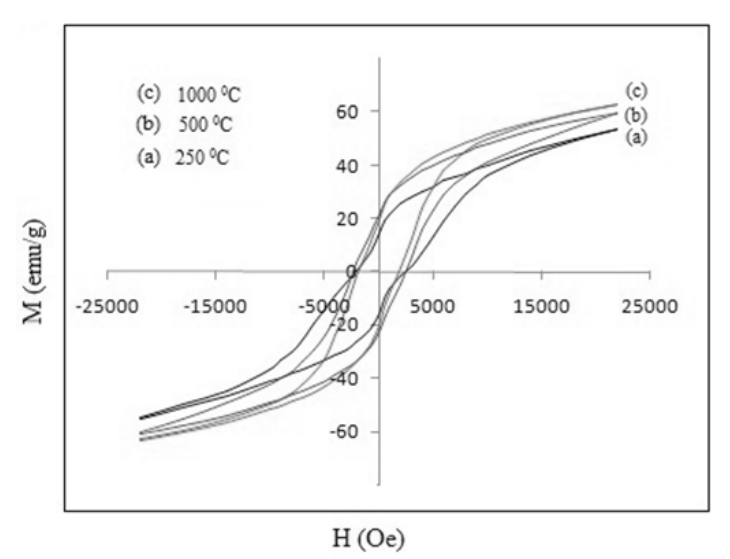

Fig. 8. Hysteresis loop of $\mathrm{CoFe}_{2} \mathrm{O}_{4}: \mathrm{SiO}_{2}$ nanocomposites annealed at different temperatures

\section{CONCLUSION}

Desirable samples of silica coated cobalt-ferrite nanocomposites have been successfully prepared with the help of co-precipitation method and then were further heat treated at different temperatures of $250^{\circ} \mathrm{C}, 500^{\circ} \mathrm{C}, 750^{\circ} \mathrm{C}$ and $1000^{\circ} \mathrm{C}$. With the help of XRD data, the lattice constant has been found to increase from $8.032 \AA$ to $8.069 \AA$ by increasing the calcinations temperature from $250^{\circ} \mathrm{C}$ to $750^{\circ} \mathrm{C}$ respectively. Nearly about $75 \%$ of crystallites are having the size range $30-42 \mathrm{~nm}$ from TEM investigations, indicates a wide grain size distribution of crystallites. Results of our research concluded that there is an increase in particle size, crystallinity, surface morphology and microstructure of nanocomposites with increasing calcinations temperature. Further, the value of saturation magnetization (Ms ) is reported $53.6 \pm 0.1 \mathrm{emu} / \mathrm{g}$ and $63.7 \pm 0.1 \mathrm{emu} / \mathrm{g}$ corresponding to the calcinations temperature $250^{\circ} \mathrm{C}$ and $1000^{\circ} \mathrm{C}$ respectively. On the basis of VSM results at room temperature, it can be concluded that magnetic properties such as retentivity, saturation magnetization and coercivity revealed a strong dependence on the crystallite size and calcinations temperature. Furthermore, non-uniform behaviour of residual magnetization may be related to surface canting or spin's non-colinearity in our synthesized nanocomposites.

\section{ACKNOWLEDGEMENT}

The University of Delhi, New Delhi and IIT, Roorkee are Gratefully Acknowledged for providing characterization facilities.

\section{REFERENCES}

1. Mnyusiwalla, A.; Daar, A.S.; Singer, P.A. Mind the gap: science and ethics in nanotechnology, Nanotechnology., 2003, 14, R9.

2. Buot, F.A. Mesoscopic physics and nanoelectronics: nanoscience and nanotechnology, Physics Reports., 1993, 234, 73-174.

3. Pardavi-Horvath, M. J. of Magn and Magn Mater., 2000, 215, 171-183.

4. Huang, X.H.; Chen, Z.H. Solid State Commun., 2004, 132, 845-850.

5. Jung, J.S.; Lim, J.H.; Choi, K.H.; Oh, S.L.; Kim, Y.R.; Lee, S.H.; Smith, D.A.; Stokes, K.L.; Maljinski, L.; Oconnor, C.J. J. Appl. Phys., 2005, 97, 10F306.

6. Virden, A.E.; Ogrady, K. J. Appl. Phys., 2006, 99, $08 \mathrm{~S} 106$.

7. Ramankutty, C.G.; Sugunan, S. Appl. Catal. A: Gen., 2001, 218, 150-1156.

8. Harris, V.G.; Chen, Z.H.; Chen, Y.J.; Yoon, S.; Sakai, T.; Gieler, A.;Yang, A.; He, Y.X.; Ziemer, K.S.; Sun, N.X.; Vittoria, C. J. Appl. Phys., 2006, 99, 08M911.
9. Jyotsnendu, G.; Theerdhala, S.; Saket, A.; Tumkur, G.R.; Arun, K.N.; Dhirendra, K.B. J. Magn. Magn. Mater., 2005, 293, 55.

10. Cullity, B.D. Elements of X-ray Diffraction, Addison-Wesley Reading MA., 1959.

11. Huang, X.; Chen, Z. J. Magn Magn Mater., 2004, 280, 37-43.

12. Chien, C.L.; Annu.Rev. Mater. Sci., 1995, 25,129.

13. Sutka, A.; Mezinskis, G. Frontiers of Materials Science., 2012, 6, 128-141.

14. Mathew, D.S.; Juang, R.S. Chemical Engineering Journal., 2007, 129, 51-65.

15. Liu, C.; Zou, B.; Rondinone, A.J.; Zhang, Z. J. J. Am. Chem. Soc., 2000, 122 , 62-63.

16. Pillai, V.; Shah, D.O. J. Magn. Magn. Mater., 1996, 163, 243.

17. Lee, J.G.; Park, J.Y. ; Kim, C.S.J. Mater. Sci. 1998, 33, 396.

18. Yeong, K.I.; Don, K.; Choong, L.S. Physica B., 2003, 337, 42.

19. Morais, P.C.; Garg, V.K.; Oliveira, A.C. ; Silva, L.P.; Azevedo, R.B.; Silva, A.M.L.; Lima, E. C.D. J. Magn. Magn. Mater., 2001, 225, 37. 
20. Xavier, S.; Thankachan, S.; Jacob, B. P.; Mohammed, E. M. Nanosystems: Phys.Chem. Math., 2013, 4, 430-437.

21. Duhan, S.;Aghamkar, P.;Kishore, N.;Lal, B.Materials Chemistry and Physics., 2009, 114 103-106.

22. Shinde, T.J.; Gadkari, A.B.; Vasambekar, P.N. J. Mater. Sci. Mater. Electron., 2010, 21, 120-124.

23. Rohilla, S.; Kumar, S.; Aghamkar, P.; Sunder S.; Agarwal, A. J. Magn.Magn. Mater., 2011, 323, 897-902.

24. Garcia Cerda, L.A.; Montemayor, S.M. J. Magn.Magn. Mater., 2005, 294, e43-e46.
25. Coey, J.M.D. Phys. Rev. Lett., 1971, 27, 1140-1142.

26. Xianghui, H.; Zhenhua; C. Chinese Sci Bull., 2006, 51, 2529-2534.

27. Xiao, S.H.; Xu, H.J.; Hu, J.; Li, L.Y.; Li, X. J.Physica E., 2008, 40, 3064-3067.

28. Liu, B.H.; Ding, J. Appl. Phys. Lett., 2006, 88, 042506-1.

29. Wang, Y.C.; Ding, J.;Yi, J.B.; Liu, B.H.;Yu, T.; Shen, Z.X. Appl. Phys. Lett., 2004, 84, 2596-2598.

30. Xiao, S. H.; Jiang, W. F.; Lia, L. Y.; Li, X. J. Mater. Chem. Phys., 2007, 106, 82-87. 